Case Report

\title{
Acute Hemolysis with Renal Failure due to Clostridium Bacteremia in a Patient with AML
}

\author{
R. M. Medrano-Juarez, D. Sotello, M. A. Orellana-Barrios, \\ L. D'Cuhna, J. D. Payne, and K. Nugent
}

Department of Internal Medicine, Texas Tech University Health Sciences Center, 3601 th Street, MS 9410, Lubbock, TX 79430, USA

Correspondence should be addressed to M. A. Orellana-Barrios; menfil@gmail.com

Received 9 June 2016; Accepted 7 September 2016

Academic Editor: Daniela M. Cirillo

Copyright ( 2016 R. M. Medrano-Juarez et al. This is an open access article distributed under the Creative Commons Attribution License, which permits unrestricted use, distribution, and reproduction in any medium, provided the original work is properly cited.

\begin{abstract}
We present a case of acute hemolytic anemia, renal failure, and Clostridium perfringens bacteremia in a patient with acute myelogenous leukemia. The high fatality of $C$. perfringens bacteremia requires that clinicians recognize and rapidly treat patients at risk for this infection. Although other hemolytic processes are in the differential diagnosis of these events, the presence of high fever, chills, and rapidly positive blood cultures may help narrow the diagnosis. Most cases of $C$. perfringens bacteremia have a concomitant coinfection, which makes broad spectrum empiric therapy essential. There is a high mortality rate of $C$. perfringens infections associated with leukemia.
\end{abstract}

\section{Introduction}

Patients with hematologic malignancies are at particularly high risk of aggressive and sometimes fatal infections. Prompt diagnosis may be clinically challenging with concomitant or differential diagnoses such as disseminated intravascular coagulation, hemolysis, tumor lysis syndrome, and thrombotic thrombocytopenic purpura. We present a case of acute hemolytic anemia, renal failure, and Clostridium perfringens bacteremia in a patient with acute myelogenous leukemia.

\section{Case Presentation}

A 32-year-old African American man initially presented with a three-day history of gingival hemorrhage, occurring after tooth extraction. He had a past medical history of possible lead poisoning as a child, hypertension, and a three-year history of thrombocytopenia presumably due to idiopathic thrombocytopenic purpura. At presentation, he was not taking any medications. He was diagnosed with acute myeloid leukemia (karyotype 47, XY + 21). He failed initial induction with cytarabine/daunorubicin and subsequently underwent reinduction with cytarabine/clofarabine.
Due to sustained severe neutropenia and fever during his inductions, he completed 25 days of empiric treatment with meropenem. Ultimately, he developed vancomycin-resistant Enterococcus faecium gluteal abscess, treated with incision and drainage and 15 days of intravenous (IV) quinupristin/dalfopristin. He then received prophylactic ciprofloxacin/ fluconazole.

Approximately seven days later his gluteal wound had almost healed, and he had been afebrile for $>10$ days. His absolute neutrophil count remained extremely low (persistently $<10$ cells $\mathrm{K} / \mathrm{uL}$ ). The patient developed sudden onset chills, body aches, fever, diaphoresis, and dark urine. Physical examination presented a patient in severe distress, with pale mucosae and mild mucositis, blood pressure $134 / 84 \mathrm{mmHg}$, heart rate 126 beats per minute, respirations 20 per minute, room air oxygen saturation $94 \%$, icteric sclera, no lymphadenopathy, clear lung sounds, normal S1 and S2 with a systolic aortic $2 / 6$ murmur, normal bowel sounds, slight abdominal distention with no tenderness, no hepatomegaly, $1.5 \mathrm{~cm}$ almost healed perianal/gluteal ulcer with no secretions or crepitus, normal genitals, mild bilateral pretibial edema, unremarkable chemotherapy port site, and no abnormal neurological findings. The patient's laboratory results differed 
TABLE 1: Laboratory values.

\begin{tabular}{|c|c|c|c|}
\hline Parameter & Previous & Day of fever & Units \\
\hline WBC & 0.1 & 0.1 & $\mathrm{~K} / \mathrm{uL}$ \\
\hline $\mathrm{RBC}$ & 2.92 & 1.63 & $\mathrm{M} / \mathrm{uL}$ \\
\hline $\mathrm{Hgb}$ & 8.6 & 5.2 & $\mathrm{~g} / \mathrm{dL}$ \\
\hline Hct & 24.1 & 13.7 & $\%$ \\
\hline $\mathrm{MCV}$ & 82.7 & 84.4 & $\mathrm{fL}$ \\
\hline $\mathrm{MCH}$ & 29.4 & 31.9 & pg \\
\hline RDW & 12.7 & 13.1 & $\%$ \\
\hline Platelet & 16 & 11 & $\mathrm{~K} / \mathrm{uL}$ \\
\hline MPV & 7.7 & 8.9 & $\mathrm{fL}$ \\
\hline $\mathrm{Na}$ & 137 & 130 & $\mathrm{mmol} / \mathrm{L}$ \\
\hline $\mathrm{K}$ & 3.8 & 4.9 & $\mathrm{mmol} / \mathrm{L}$ \\
\hline $\mathrm{Cl}$ & 100 & 96 & $\mathrm{mmol} / \mathrm{L}$ \\
\hline $\mathrm{Mg}$ & 1.6 & 1.5 & $\mathrm{mg} / \mathrm{dL}$ \\
\hline $\mathrm{Ca}$ & 8.8 & 8 & $\mathrm{mg} / \mathrm{dL}$ \\
\hline $\mathrm{Ph}$ & 3.7 & 2 & $\mathrm{mg} / \mathrm{dL}$ \\
\hline Bicarb & 25 & 20 & $\mathrm{mmol} / \mathrm{L}$ \\
\hline BUN & 15 & 37 & $\mathrm{mg} / \mathrm{dL}$ \\
\hline Creatinine & 1.2 & 2.4 & $\mathrm{mg} / \mathrm{dL}$ \\
\hline Uric acid & & 4.3 & $\mathrm{mg} / \mathrm{dL}$ \\
\hline Total bilirubin & 1.7 & 13.4 & $\mathrm{mg} / \mathrm{dL}$ \\
\hline Direct bilirubin & & 8.3 & $\mathrm{mg} / \mathrm{dL}$ \\
\hline $\mathrm{LDH}$ & 120 & 1132 & $\mathrm{IU} / \mathrm{L}$ \\
\hline ALT & 97 & 130 & IU/L \\
\hline AST & 167 & 36 & IU/L \\
\hline PT & & 18 & seg \\
\hline INR & & 1.6 & \\
\hline PTT & & 58.2 & $\mathrm{sec}$ \\
\hline Fibrinogen & & 517 & $\mathrm{mg} / \mathrm{dL}$ \\
\hline $\mathrm{D}$ dimer & & 6200 & $\mathrm{ng} / \mathrm{mL}$ \\
\hline Coombs & & Positive & \\
\hline Haptoglobin & & $<15$ & $\mathrm{mg} / \mathrm{dL}$ \\
\hline vWF protease activity & & 64 & $\%$ \\
\hline
\end{tabular}

significantly from the previous day (Table 1). Notably, he had evidence of acute hemolytic anemia and acute renal failure.

$\mathrm{He}$ was again started on empiric antibiotics, including IV meropenem, levofloxacin, daptomycin, and voriconazole. Peripheral blood smear showed severe pancytopenia with some schistocytes. Blood cultures were drawn, and within 12 hours Gram stain of blood culture medium showed Grampositive rods. Final growth was reported 24 hours later as Clostridium perfringens and Enterococcus faecalis (vanA and vanB negative). Antibiotics were adjusted to IV penicillin $G$ and daptomycin, which he continued for 8 days. His hemolysis, renal failure, and fever improved within 48 hours, but his ANC was persistently low despite filgrastim therapy. He required temporary hemodialysis due to renal failure but recovered renal function within eight weeks. The patient's bacteremia was resolved within 48 hours. Approximately 12 weeks later, a follow-up peripheral blood smear showed persistent leukemic blasts. At this point, the patient decided against further treatment and opted for hospice care.

\section{Discussion}

Clostridium spp. are anaerobic Gram-positive rods capable of forming endospores which make them resilient in harsh environmental conditions and ubiquitous in nature. Although Clostridium spp. constitute normal gastrointestinal or genital flora, several clostridial species are associated with human disease either by direct tissue infection (e.g., C. perfringens and C. septicum) or by toxin production (e.g., C. difficile, C. botulinum, and C. tetani) [1].

C. perfringens is classically associated with myonecrosis, or gas gangrene, and food poisoning. The pathophysiology of myonecrosis involves several exotoxins, including lecithinase, an alpha-toxin with phospholipase activity [2]. Acute hemolysis due to this alpha-toxin has been reported in up to $15 \%$ of patients with C. perfringens bacteremia [3]. Predisposing risk factors for C. perfringens infections include renal failure [4], diabetes [5], inflammatory bowel disease [6], diverticulitis and appendicitis $[7,8]$, gastrointestinal surgery [9], solid tumors [10], stem cell transplant [11, 12], lymphoma [13], and leukemia $[14,15]$.

As seen in our patient, $C$. perfringens bacteremia in patients with leukemia frequently occurs concomitant with other bacteria. For example, Bodey et al. [10] reported that 20 of $47 \mathrm{C}$. perfringens bacteremia cases were polymicrobial. In this report, the response rate was lower in the polymicrobial group (30\% versus 52\%). We performed a PubMed search of adult cases of $C$. perfringens infections associated with leukemias. A total of 19 reported cases ( 7 female, 12 male) were found $[3,10,11,14-17]$, with a mean age of 47.5 years (see Table 2). Including our case, survival was estimated at $15 \%$, demonstrating high fatality associated with $C$. perfringens infections.

Prompt recognition and rapid initiation of appropriate antibiotic therapy are essential to increase survival in $C$. perfringens infections, particularly in immunosuppressed patients. The rapid onset of systemic inflammatory response, hemolysis, and possibly renal failure should prompt the consideration of clostridial disease. The differential diagnosis includes hemolytic uremic syndrome and disseminated intravascular coagulation, which can occur in sepsis and in patients with lymphoproliferative disorders. The presence of high fever, bacteremia, rapid deterioration with hemolysis, renal failure, and shock may also provide clues to narrow the diagnosis. Empiric treatment, usually with penicillin, clindamycin, metronidazole, or cephalosporins, should be started without delay while awaiting cultures. There is some evidence that certain antibiotics, such as clindamycin and tetracycline, have greater ability to inhibit toxin synthesis, and this may produce a therapeutic benefit [18]. Surgical intervention and the combination of penicillin and clindamycin have also been reported as factors significantly associated with improved survival [13].

\section{Conclusion}

A high index of suspicion must be maintained for C. perfringens infection in patients at risk given the possibility of rapid deterioration with shock, acute massive hemolysis, and 
TABLE 2

\begin{tabular}{|c|c|c|c|c|}
\hline Authors & Age & Sex & Leukemia type & Survival \\
\hline Ifthikaruddin and Holmes [16] & 54 & $\mathrm{~F}$ & AML & $\mathrm{N}$ \\
\hline van Bunderen et al. [3] & 73 & $\mathrm{~F}$ & CLL & $\mathrm{N}$ \\
\hline Vaiopoulos et al. [15] & 74 & M & AML & $\mathrm{N}$ \\
\hline Pirrotta et al. [14] & 50 & M & ALL & $\mathrm{N}$ \\
\hline \multirow[t]{7}{*}{ Kapoor et al. [17] } & 58 & M & AML & $\mathrm{N}$ \\
\hline & 30 & $\mathrm{~F}$ & NSAL & $\mathrm{N}$ \\
\hline & 27 & $\mathrm{~F}$ & NSAL & $\mathrm{N}$ \\
\hline & 47 & M & NSAL & $\mathrm{Y}$ \\
\hline & 64 & M & NSAL & $\mathrm{N}$ \\
\hline & 53 & $\mathrm{~F}$ & NSAL & $\mathrm{N}$ \\
\hline & 58 & F & NSAL & $\mathrm{N}$ \\
\hline \multirow[t]{7}{*}{ Bodey et al. [10] } & 50 & M & NSAL & $\mathrm{N}$ \\
\hline & 37 & M & NSAL & $\mathrm{N}$ \\
\hline & 20 & M & NSAL & $\mathrm{Y}$ \\
\hline & 53 & M & NSAL & $\mathrm{N}$ \\
\hline & 19 & M & NSAL & $\mathrm{N}$ \\
\hline & 60 & M & NSAL & $\mathrm{N}$ \\
\hline & 19 & $\mathrm{~F}$ & NSAL & $\mathrm{N}$ \\
\hline Lee et al. [11] & 57 & M & ALL & $\mathrm{N}$ \\
\hline Our case & 32 & M & AML & $\mathrm{Y}$ \\
\hline
\end{tabular}

AML: acute myelogenous leukemia; CLL: chronic lymphocytic leukemia; NSAL: nonspecified acute leukemia; ALL: acute lymphocytic leukemia; N: no survival; Y: survival.

acute renal failure. Although other hemolytic processes are in the differential diagnosis of these events, the presence of high fever, chills, and rapidly positive blood cultures may help narrow the diagnosis. Most cases of $C$. perfringens bacteremia have a concomitant coinfection, which makes broad spectrum empiric therapy essential. There is a high mortality rate of $C$. perfringens infections associated with leukemia.

\section{Competing Interests}

The authors declare that there is no conflict of interests regarding the publication of this paper.

\section{References}

[1] F. A. Uzal, J. C. Freedman, A. Shrestha et al., "Towards an understanding of the role of Clostridium perfringens toxins in human and animal disease," Future Microbiology, vol. 9, no. 3, pp. 361-377, 2014.

[2] J. Sakurai, M. Nagahama, and M. Oda, "Clostridium perfringens alpha-toxin: characterization and mode of action," Journal of Biochemistry, vol. 136, no. 5, pp. 569-574, 2004.

[3] C. C. van Bunderen, M. K. Bomers, E. Wesdorp, P. Peerbooms, and J. Veenstra, "Clostridium perfringens septicaemia with massive intravascular haemolysis: a case report and review of the literature," Netherlands Journal of Medicine, vol. 68, no. 9, pp. 343-346, 2010

[4] C.-C. Yang, P.-C. Hsu, H.-J. Chang, C.-W. Cheng, and M.H. Lee, "Clinical significance and outcomes of Clostridium perfringens bacteremia-a 10-year experience at a tertiary care hospital," International Journal of Infectious Diseases, vol. 17, no. 11, pp. e955-e960, 2013.

[5] A. E. Mirrakhimov, G. Chandra, P. Voore et al., "Clostridium perfringens bacteremia in an 85-year-old diabetic man," Case Reports in Gastroenterology, vol. 8, no. 3, pp. 404-407, 2014.

[6] A. Banaszkiewicz, J. Kadzielska, A. Gawrońska et al., "Enterotoxigenic Clostridium perfringens infection and pediatric patients with inflammatory bowel disease," Journal of Crohn's and Colitis, vol. 8, no. 4, pp. 276-281, 2014.

[7] A. Atia, T. Raiyani, P. Patel, R. Patton, and M. Young, "Clostridium perfringens bacteremia caused by choledocholithiasis in the absence of gallbladder stones," World Journal of Gastroenterology, vol. 18, no. 39, pp. 5632-5634, 2012.

[8] P. M. Rechner, W. A. Agger, K. Mruz, and T. H. Cogbill, "Clinical features of clostridial bacteremia: a review from a rural area," Clinical Infectious Diseases, vol. 33, no. 3, pp. 349-353, 2001.

[9] A. Schwan and A. C. Ryden, "The clinical importance of anaerobic bacteria in wound infections after gastrointestinal surgery," Scandinavian Journal of Infectious Diseases, vol. 10, no. 2, pp. 119-125, 1978.

[10] G. P. Bodey, S. Rodriguez, V. Fainstein, and L. S. Elting, "Clostridial bacteremia in cancer patients. A 12-year experience," Cancer, vol. 67, no. 7, pp. 1928-1942, 1991.

[11] H.-L. Lee, S.-Y. Cho, D.-G. Lee et al., "A fatal spontaneous gas gangrene due to Clostridium perfringens during neutropenia of allogeneic stem cell transplantation: case report and literature review," Infection and Chemotherapy, vol. 46, no. 3, pp. 199-203, 2014.

[12] E. Renaudon-Smith, M. Kaur, A. Haroon, J. Cavenagh, and T. Butler, "Intravascular haemolysis secondary to Clostridium perfringens in a patient with acute myeloid leukaemia undergoing allogeneic stem cell transplantation," British Journal of Haematology, vol. 165, no. 6, p. 743, 2014.

[13] T. G. Simon, J. Bradley, A. Jones, and G. Carino, "Massive intravascular hemolysis from clostridium perfringens septicemia: a review," Journal of Intensive Care Medicine, vol. 29, no. 6, pp. 327-333, 2014.

[14] M. T. Pirrotta, A. Bucalossi, F. Forconi et al., "Massive intravascular hemolysis: a fatal complication of Clostridium perfringens septicemia in a patient with acute lymphoblastic leukemia," Leukemia \& Lymphoma, vol. 46, no. 5, p. 793, 2005.

[15] G. Vaiopoulos, C. Calpadaki, H. Sinifakoulis et al., "Massive intravascular hemolysis: a fatal complication of clostridium perfringens septicemia in a patient with acute myeloid leukemia," Leukemia and Lymphoma, vol. 45, no. 10, pp. 2157-2159, 2004.

[16] J. J. Ifthikaruddin and J. A. Holmes, "Clostridium perfringens septicaemia and massive intravascular haemolysis as a terminal complication of autologous bone marrow transplant," Clinical and Laboratory Haematology, vol. 14, no. 2, pp. 159-161, 1992.

[17] J. R. Kapoor, B. Monteiro, L. Tanoue, and M. D. Siegel, "Massive intravascular hemolysis and a rapidly fatal outcome," Chest, vol. 132, no. 6, pp. 2016-2019, 2007.

[18] D. L. Stevens, K. A. Maier, and J. E. Mitten, "Effect of antibiotics on toxin production and viability of Clostridium perfringens," Antimicrobial Agents and Chemotherapy, vol. 31, no. 2, pp. 213218, 1987. 


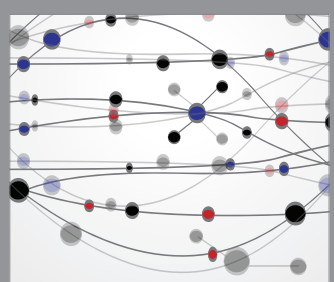

The Scientific World Journal
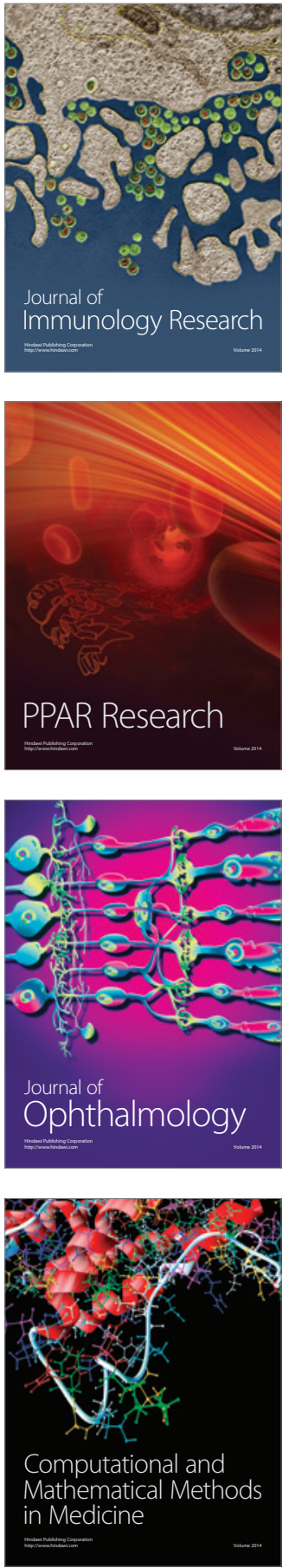

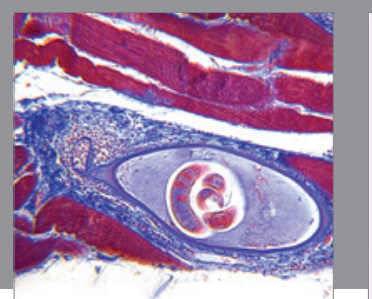

Gastroenterology Research and Practice

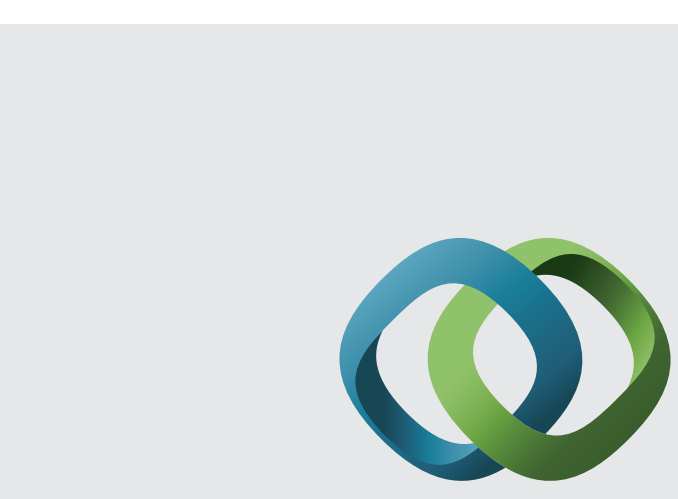

\section{Hindawi}

Submit your manuscripts at

http://www.hindawi.com
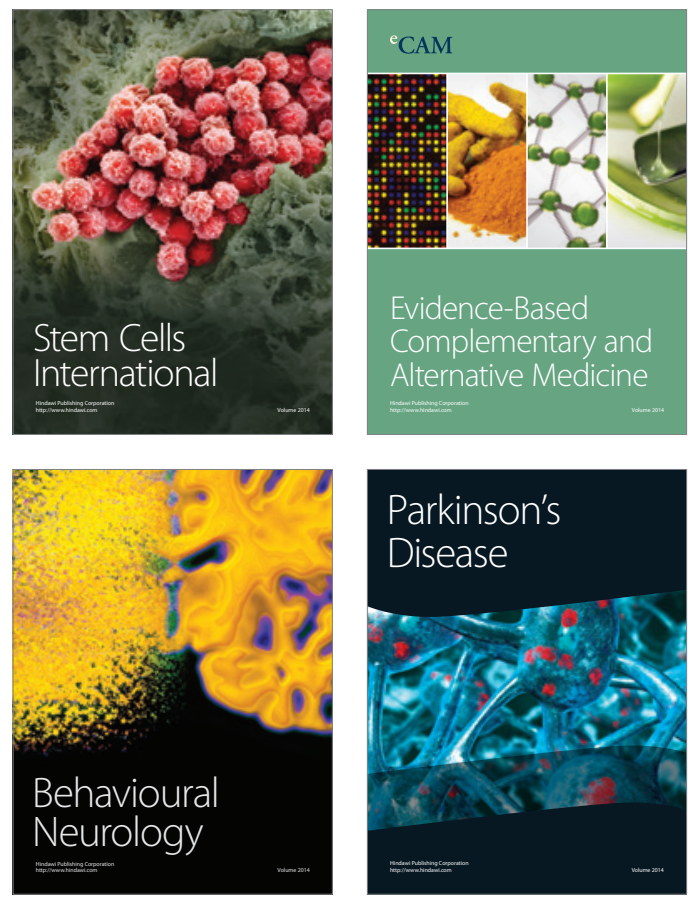
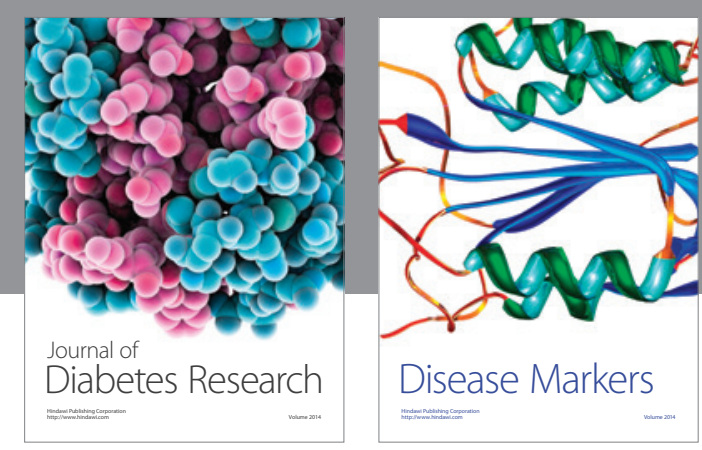

Disease Markers
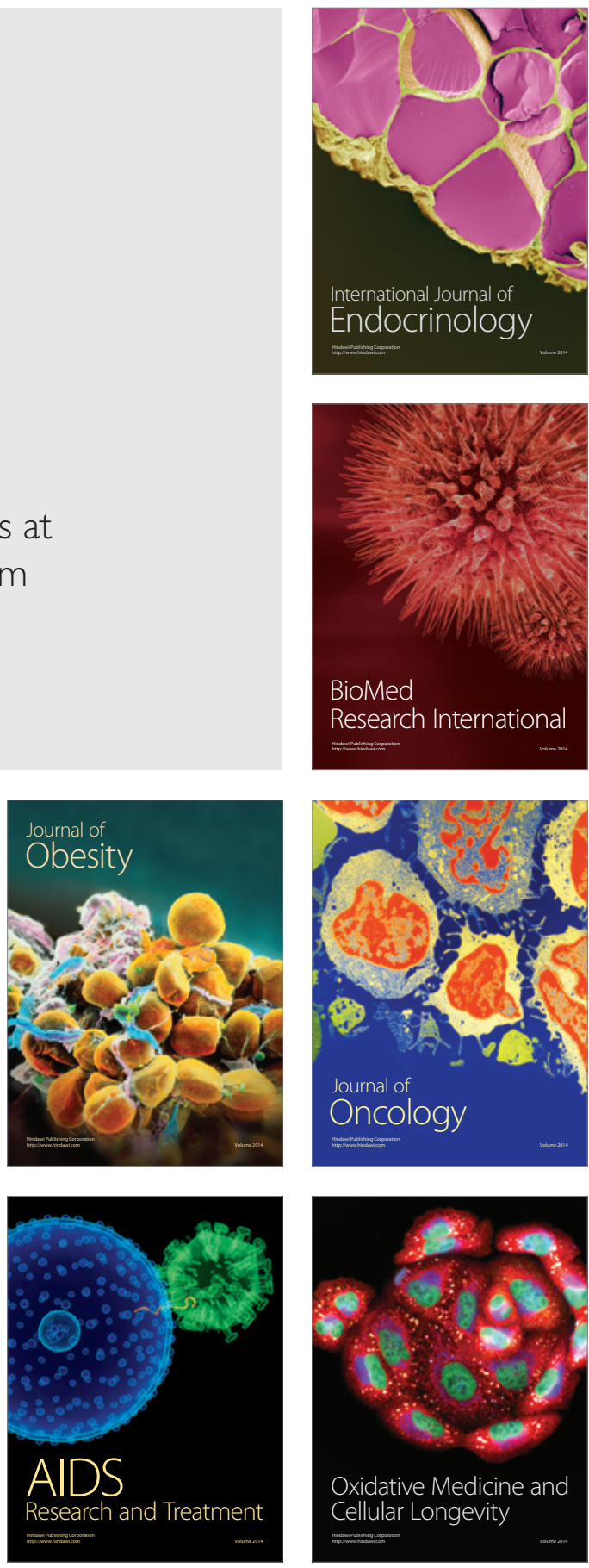